\title{
THE TOURIST AND TOURISM GAZES UPON CRADLE MOUNTAIN AND FREYCINET NATIONAL PARK
}

\author{
by Chantelle Ridley
}

(with four text-figures and four tables)

Ridley, C. 2020 (9:xii): The tourist and tourism gazes upon Cradle Mountain and Freycinet National Park. Papers and Proceedings of the Royal Society of Tasmania 154: 27-35. https://doi.org/10.26749/rstpp.154.27 ISSN: 0080-4703. 6 Braelands Court, South Hobart, Tasmania, Australia 7004. Email: chantelle.ridley17@gmail.com

The natural aesthetic resource is an important element of natural and cultural heritage and an attractor of tourists. It is important for heritage management to understand the scenic attractors of tourists. Photographs of Cradle Mountain (150) and Freycinet National Park (149) were collected from a range of sources to determine whether there is a constancy of gaze between those who promote tourism and those who tour, and between the two visually distinct destinations. Publicly available images from four different sources were used to compare content attributes and mise en scène attributes between localities using Chi-square and ANOSIM. The photographs were then ordinated using the same attributes, and the results were displayed using photographic average composites. The Discover Tasmania and Google Images photographs were similar, both better conforming to advanced compositional principles compared to the Instagram and promotional images, which were similar, especially in the featuring of people in landscape foregrounds. There may be a reciprocal interaction between promotional and tourist images, rather than a one-way process. The contrasting features in the images from the two places were largely a product of the very different physical environments. However, the photographs at Freycinet were taken from several geographic locations, whereas the vista of Dove Lake and Cradle Mountain dominated all image sources at Cradle Mountain. The content analysis of the images was consistent between places, except where a feature of an artefact or natural feature created opportunity for artistic expression. Key Words: aesthetic resource, content analysis, Discover Tasmania, Google Images, Instagram, mise en scène, images, promotional images.

\section{INTRODUCTION}

"Nature was tamed, put into perspective with, and by, the human eye, as a landscape picture, a single vision of order." (Urry \& Larson 2011, p. 131)

Wilderness landscapes, once terrifying and depressing, are now places for pleasure, solitude and contemplation (Schirpke et al. 2013). Natural aesthetic resources that tend towards the sublime (Beza 2010, Kirillova et al. 2014) are an intangible asset in protected areas (Mendel \& Kirkpatrick 1999) as they attract tourists, and therefore economic development.

In 2019, most tourists have the technological means to immediately and globally communicate their arrival at a tourist icon through social media via image and hashtagged caption. The presence of tourists at scenic icons may be motivated by the images of previous visitors, or by the images presented by professional agents. These sources indicate destinations in which tourists can view the extraordinary (Stylianou-Lambert 2012). Phelps (1986) classifies promotional images as secondary images and images generated by tourists as primary. Tourists are regarded as passive consumers of scenes by replicating the images they see in promotional material; or as active participants, recreating scenes through the lens of their own experiences (Stylianou-Lambert 2012). The latter perspective may be particularly apposite to social networking sites, such as Instagram.
There are few published comparisons between primary and secondary images (Stephchenkova \& Zhan 2013, Paül i Agustí 2018). Sources are usually treated independently and are examined through the lens of a single discipline (Stylianou-Lambert 2012). It is important to examine primary and secondary sources though a multidisciplinary lens, to extend our understanding of tourist behaviour and perception. One widely used method to quantify visual preferences for landscapes is content analysis (Linton 1968, Wang et al. 2016, Tieskens et al. 2018, Pickering et al. 2020). Content analysis examines landscape elements within an image, such as quality and quantity of vegetation, distance to vegetation, water bodies (Shafer \& Brush 1977, Patsfall et al. 1984) and mountains (Mendel \& Kirkpatrick 1999).

Integrating content analysis with mise en scène techniques may reveal hidden relationships previously not studied in destination imagery. Mise en scène, or 'to appear on stage' is a traditional theatrical technique used to convey narrative and mood, via composition, lighting, setting and clothing (Giannetti 2014). This same technique is applied cinematically and photographically, within a frame. Preferences for, and perceptions of, desirable landscapes are influenced by position on the continuum from realistic to abstract representation in destination images (Daniel \& Meitner 2001).

The social media component of the study was conducted using the smartphone image-sharing platform 'Instagram', which allows users to share images publicly or privately. 
Instagram was chosen because of its popularity in the current social climate (Choi \& Sung 2018) and its use in recent studies on its application by tourists (University of Tasmania 2019). However, using Instagram has limitations as the samples include only images from accounts that have been made publicly accessible. Images are in Instagram using keywords that relate to either a title (user), geotag (location) or a hashtag (category). Location can easily and automatically be applied to an image if the GPS services are activated on the device. Hashtags are used to categorise the image to reach niche demographics.

Data visualisation is the transformation of quantitative or qualitative data into graphic representation. When large and complicated data sets are transformed into aesthetic graphics, information becomes accessible, comparable and better understood among general audiences (Felton et al. 2016).

Photographic averaging composites are a post processing method that aligns and blends photographs together (Felton et al. 2016). This method has been widely used to illustrate specific collectives, such as in portraiture to find the average face and the similarity of photographs taken of tourism icons (Felton et al. 2016, Bergh et al. 2018).

In this study the contents and mise en scène of images were compared to determine whether there is a constancy of gaze between those who promote tourism and those who tour, and between two visually distinct destinations. I determined whether contents and artistic designs differ between images collected from four distinct sources: printed promotional material (i.e., tourism brochures), Discover Tasmania Instagram site (henceforth Discover Tasmania), Google Images and Instagram. I used the two most iconic national park destinations in Tasmania: Freycinet and Cradle Mountain. Photographic average composites illustrate the differences between sources.

\section{METHODS}

\section{The study area}

Tasmania $\left(41.640079^{\circ} \mathrm{S}, 146.315918^{\circ} \mathrm{E}\right)$ is an island state of Australia, located $240 \mathrm{~km}$ south of the mainland (fig. 1). Tasmania has a population of 529,903 (Australian Bureau of Statistics 2018) in a total area of $68,401 \mathrm{~km}^{2}$ (Geoscience Australia 2020). The rich and distinctive geodiversity and biodiversity of the island result in natural landscapes of great beauty. Tasmania has $42 \%$ (2.9 million ha) of its land dedicated to national parks and reserves (Tasmania Parks \& Wildlife Service 2020) with 1.58 million ha of this in the Tasmanian Wilderness World Heritage Area, declared for both cultural and natural values (DPIPWE 2016). Tourism campaigns promote natural features, gourmet produce, wildlife and the arts (Tourism Tasmania 2016). Before the impact of the Covid-19 pandemic, tourism directly and indirectly contributed $\$ 3.03$ billion (10.4\%) to Tasmania's Gross State Product (Tourism Tasmania 2019a). In 2017-2018, 1.32 million people visited the state with 307,000 international visitors and 1.09 million arriving

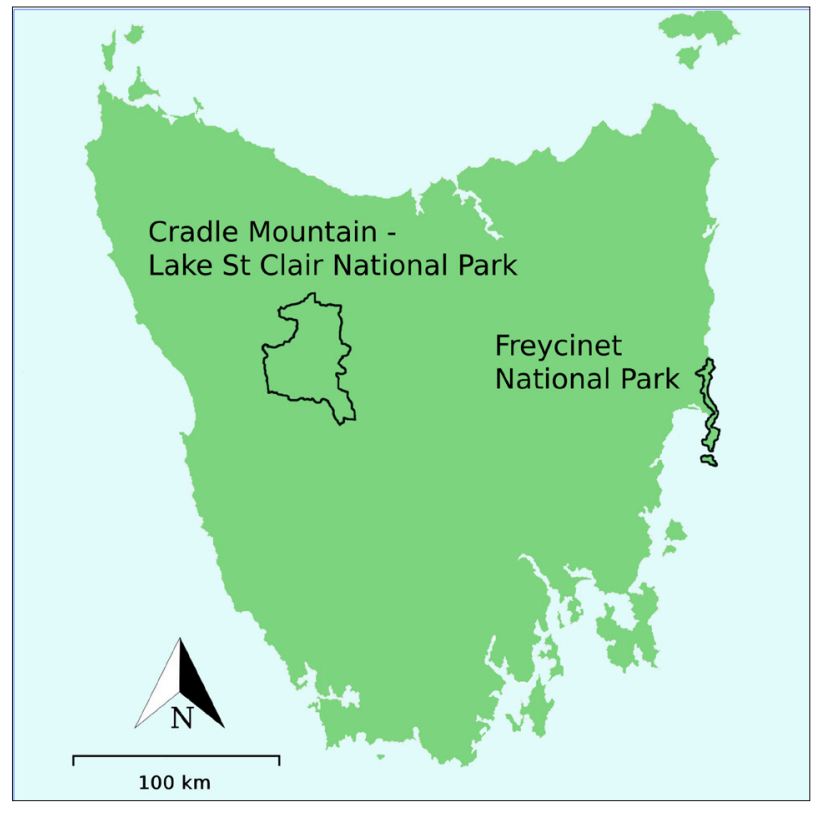

FIG. 1 - The island state of Tasmania showing the study areas of Freycinet National Park and Cradle Mountain-Lake St Clair National Park.

from interstate (Tourism Tasmania 2019a, b). International and interstate tourists on holiday are more likely to visit a national park than those visiting Tasmania for business activities or to visit friends and relatives (Tasmania Parks \& Wildlife Service 2019).

\section{Site selection}

Two popular, and environmentally different, tourism icons were chosen for the study (fig. 1). The coastal Freycinet National Park has the highest number of visitors of any national park in the State (Tasmania Parks $\&$ Wildlife Service 2019). The subalpine/montane Cradle Mountain, located to the west, is the second most visited location in the national park estate (Tasmania Parks \& Wildlife Service 2019).

\section{Selection of images}

Images were selected if they satisfied the following criteria: - images were taken within the park boundary and viewpoints were accessible without overnight camping;

- images were of landscapes.

Images were collected from tourist information brochures, social media and the web using the Google Images search engine. All images were collected in the 2018-2019 summer peak tourism season. All data were manually retrieved.

Printed promotional material was used to obtain the images that private companies used to attract customers. This material consisted of brochures advertising accommodation and private tours. Printed promotional material was collected from three tourist information centres in Tasmania in February 2019. All images from the study areas were used.

A Google Images search on the web was conducted using variants of the locality names. The keywords 'Freycinet' 
and 'Cradle Mountain' received the highest number of images. It was assumed that images that first appeared in the search would be more likely to represent professional material, as advanced development of their website/image allowed the image to be there in the first place. Images were sampled sequentially from the first image.

For Instagram (i.e., a photo and video sharing social networking service owned by Facebook), it was decided that location was to be used to select images as more images per day were uploaded using location than those hashtagged. Images were selected from 'Freycinet National Park' and 'Cradle Mountain', between 1 October 2018 and 31 March 2019, using a random number generator.

Tourism Tasmania's Official Instagram account 'Discover Tasmania' (https://www.instagram.com/tasmania/) was used to represent destination images promoted by the State Government. 'Discover Tasmania' is created through usergenerated content where hashtagging \#discovertasmania or \#tassiestyle, gives permission for the organisation to use the image in online promotions.

Two hundred and ninety-nine images were sampled (table 1). All were freely available to the public. One hundred images were from promotional/professional sources, 100 from recreational and 99 from a professional source using recreational user-generated images. A running mean for the presence of water in randomly selected images from the selection was calculated. The presence of water in an image equalled one and its absence zero. This mean stabilised at around 25 images. The process was repeated with mountains, with the same outcome.

\section{Content analysis - location and subjects}

The most popular viewpoints for each media type at Cradle and Freycinet were determined using the author's knowledge of the areas. Local knowledge was required to assess the location of the image. Location was coded as marine, if it was taken on the water, and by the nearest geographical feature if terrestrial. When available, captions and hashtags were used to cross-validate these data. The percentage of images taken at each geographical location in each national park was calculated to determine which were the most popular sites to photograph across all media sources and within and between national parks (fig. $2 \mathrm{a}$ and $2 \mathrm{~b}$ ).

The presence/absence of landscape elements were recorded. These were: water bodies, mountains and vegetation as a feature (e.g., tree trunks, shrubbery, cushion plant). The measurement method of Oktas was used to determine cloud cover and as an estimate of the weather conditions: clear: $0-10 \%$, scattered: $10-50 \%$, broken: $50-$ 90\%, overcast: $90-100 \%$. Artefacts included monuments (lighthouse, shed, accommodation, hut), infrastructure (boardwalk, trail, railing, sign), transportation (boat, car, plane, kayak, paddleboard), natural features (rock, geology, driftwood, milky way), weather phenomena (snow, mirrored reflections on still water), animals and toys.

\section{Mise en scène criteria}

The mise en scène component of lighting, conveying mood, tone and focus within the frame was captured in six time-ofday categories (sunrise, early morning, day, late afternoon, sunset, night). Shot and camera proxemics describe how much of the subject is in the frame and how much of the human subject is within the frame. Each image was classified as either terrestrial, marine or aerial. The nature of the composition of the image was recorded for each of: the rule of thirds in which the subject matter is organised in nine equal rectangles, with important details placed off centre where the lines intersect; the use of the golden rule; the use of geometric features in the image; the use of features as leading lines; central location; and, split design in which there is symmetry in the image. Three characteristic depths of field were recorded.

\section{Data analysis}

Chi-squared was used for individual class variables to determine whether there was deviation from random in data related to source (promotional, Instagram, Discover Tasmania and Google Images) or location (Freycinet, Cradle Mountain). Pearson's Method was used to determine the $p$ value. These analyses were done in Minitab18.

Non-metric multidimensional scaling was used to ordinate the images using the qualitative $(1 / 0)$ content and mise en scène variables listed above. The default options in DECODA were used for this process. An ANOSIM analysis of differences between the combination of places and sources was undertaken in DECODA using the scores on the four dimensions of the ordination with the use of 10,000 permutations to calculate the probabilities associated with the $\mathrm{R}$ statistic. In all analyses the null hypothesis was rejected if $p<0.05$.

TABLE 1 - The most photographed locales at Cradle Mountain and Freycinet National Park by source, showing the number of images for the source by locality.

\begin{tabular}{lcclccc}
\hline Image source & \multicolumn{2}{c}{ Freycinet National Park } & & \multicolumn{2}{c}{ Cradle Mountain } \\
\cline { 2 - 3 } \cline { 5 - 6 } & No. & Most Frequent & & No. & Most Frequent \\
\hline Promotional & $7 / 22$ & Wineglass Lookout & & $6 / 23$ & Dove Lake \\
Google Images & $9 / 28$ & Freycinet Peninsula & & $5 / 27$ & & Dove Lake \\
Instagram & $11 / 50$ & Wineglass Lookout & & $8 / 50$ & & Dove Lake \\
Discover Tasmania & $10 / 49$ & Mount Amos & & $11 / 50$ & & Dove Lake \\
\hline
\end{tabular}



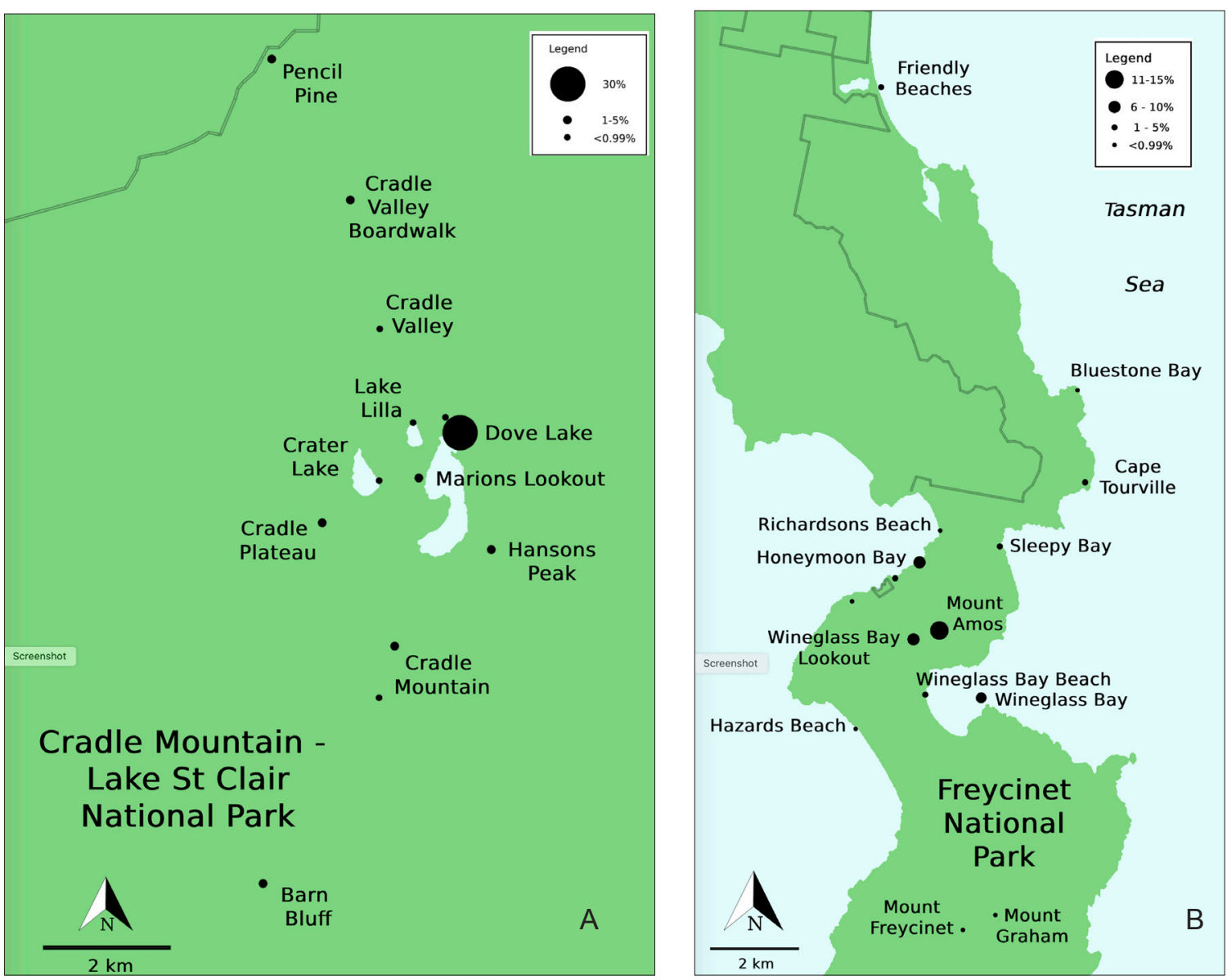

FIG. 2 - Percentage of images taken at geographical locations across all media sources at (A) Cradle Mountain and (B) Freycinet, Tasmania.

\section{Creation of photographic average composites}

The photographic average composites (PAC) were based on the significant results derived from the mise en scène and content analysis. The process was applied to one or a few locales with the highest frequency of images. The iconic landscape value informed the centre point. Having this visual anchor creates greater harmony in the PAC and a pivot for the remaining scene to play out.

To construct the PAC, landscape long shot images of the most photographed locale were selected from each source type. Printed promotional material was not used to construct a PAC as it required digitisation and there was excess visual noise with the graphic design.

Images were not resized so as to retain the quality of the information. PAC were constructed on a large blank project and were not cropped in the final presentation. This was both an aesthetic and data integrity decision, as the final presentation revealed information about the original orientation of the images. The one exception to this rule were the Google Images shots of Freycinet. These images were aerial and therefore did not have an optimal viewpoint or consistency in landscape shot types. Due to a low number of images, all shot types had to be utilised. The decision to resize the images was based on aesthetics, as the alterations created a more visually harmonious PAC.
Images that are closest to the front of the stack provide the details (Felton et al. 2016).

\section{RESULTS}

Freycinet had a higher number of locales photographed compared to Cradle Mountain (table 1, fig. 2). Thirty percent of the 299 images that were photographed were at Dove Lake below Cradle Mountain, followed by Mount Amos (14\%), Wineglass Bay Lookout (8\%) and Honeymoon Bay (6.4\%) all at Freycinet. The most photographed locale was constant between sources for Cradle Mountain (table 1).

The stress for the four-dimensional ordination was 0.163 . The overall ANOSIM R value for the differentiation by source and place was $0.0276(p=0.012)$. There was significant differentiation between all combinations of place and medium with Discover Tasmania and Instagram images (table 2). There was also significant differentiation between all combinations of place and medium with promotional images and Google Images (table 2). Thus, Discover Tasmania images were similar to Google and promotional images. Instagram images were also similar to Google and promotional images. Promotional images and Google Images shots were similar to Discover Tasmania and Instagram images (table 2). 
TABLE 2 - Combinations of place and source that were significantly different on the four-dimensional ordination scores for all qualitative variables (ANOSIM R-statistic).

\begin{tabular}{lcccccccc}
\hline & $\mathrm{DF}$ & $\mathrm{DC}$ & $\mathrm{IF}$ & $\mathrm{IC}$ & $\mathrm{PF}$ & $\mathrm{PC}$ & $\mathrm{GF}$ & $\mathrm{GC}$ \\
\hline $\mathrm{DF}$ & $\mathrm{X}$ & $*$ & $*$ & $* * *$ & - & - & - & - \\
$\mathrm{DC}$ & $*$ & $\mathrm{X}$ & $*$ & $* * *$ & - & - & - & - \\
$\mathrm{IF}$ & $*$ & $*$ & $\mathrm{X}$ & $*$ & - & - & - & - \\
$\mathrm{IC}$ & $* * *$ & $* * *$ & $*$ & $\mathrm{X}$ & - & - & - & - \\
$\mathrm{PF}$ & - & - & - & - & $\mathrm{X}$ & $*$ & $* *$ & $* * *$ \\
$\mathrm{PC}$ & - & - & - & - & $*$ & $\mathrm{X}$ & $* *$ & $*$ \\
$\mathrm{GF}$ & - & - & - & - & $* *$ & $* *$ & $\mathrm{X}$ & $* *$ \\
$\mathrm{GC}$ & - & - & - & - & $* * *$ & $*$ & $* *$ & $\mathrm{X}$ \\
\hline
\end{tabular}

${ }^{* * *}=p<0.001,{ }^{* *}=p<0.01,{ }^{*}=p=/<0.05,-=p>0.05 . \mathrm{X}$ marks no results as self-comparison. $\mathrm{DF}=$ Discovery Tasmania/Freycinet, $\mathrm{DC}=$ Discovery Tasmania/Cradle, IF $=$ Instagram/Freycinet, IC $=$ Instagram/ Cradle, $\mathrm{PF}=$ Promotional $/$ Freycinet, $\mathrm{PC}=$ Promotional $/$ Cradle, $\mathrm{GF}=$ Google $/$ Freycinet, $\mathrm{GC}=$ Google $/$ Cradle.

TABLE 3 - The percentage frequency of content and mise en scène variables by source for those that vary significantly (Chi-squared).

\begin{tabular}{lccccc} 
Variable & $\begin{array}{c}\text { Discover } \\
\text { Tasmania }\end{array}$ & $\begin{array}{c}\text { Google } \\
\text { Images }\end{array}$ & Instagram & Promotional & P-Value \\
\hline Extended long shot & 14 & $\mathbf{2 9}{ }^{1}$ & 6 & 20 & $<0.001$ \\
Geometry & $\mathbf{3 4}$ & 20 & 22 & 4 & $<0.001$ \\
Thirds & 17 & 51 & 32 & $\mathbf{7 6}$ & $<0.001$ \\
Terrestrial & 88 & 82 & 95 & $\mathbf{9 8}$ & 0.012 \\
Water & 82 & $\mathbf{9 8}$ & 89 & 82 & 0.020 \\
Mountains & 88 & 87 & 68 & $\mathbf{8 9}$ & 0.001 \\
Day & 44 & 80 & 86 & $\mathbf{9 3}$ & $<0.001$ \\
Very wide shot figure & 33 & 11 & 16 & $\mathbf{3 8}$ & $<0.001$
\end{tabular}

${ }^{1}$ The higher percentage is shown in bold.

TABLE 4 - The percentage frequency of content and mise en scène variables by place for those that varied significantly (Chi-squared).

\begin{tabular}{lccc}
\hline Variable & Cradle & Freycinet & P-Value \\
\hline Geometry & 17 & $\mathbf{2 9}{ }^{1}$ & 0.018 \\
Split & $\mathbf{1 2}$ & 5 & 0.023 \\
Terrestrial & $\mathbf{1 0 0}$ & 81 & $<0.001$ \\
Aerial & 0 & $\mathbf{1 3}$ & $<0.001$ \\
Water & 78 & $\mathbf{9 7}$ & $<0.001$ \\
Mountains & $\mathbf{8 6}$ & 77 & 0.035 \\
Scattered clouds & 26 & $\mathbf{4 2}$ & 0.003 \\
Broken clouds & $\mathbf{2 5}$ & 15 & 0.046 \\
Landscape vegetation & 92 & $\mathbf{9 7}$ & 0.041 \\
Feature vegetation & $\mathbf{1 6}$ & 7 & 0.011 \\
Medium close-up & $\mathbf{1 1}$ & 3 & 0.006 \\
figures & & & \\
Boardwalk & $\mathbf{1 2}$ & 5 & 0.023 \\
Rock & 13 & $\mathbf{2 3}$ & 0.015 \\
Reflection & $\mathbf{7}$ & 0 & 0.001 \\
\hline
\end{tabular}

${ }^{1}$ The higher percentage is shown in bold. 

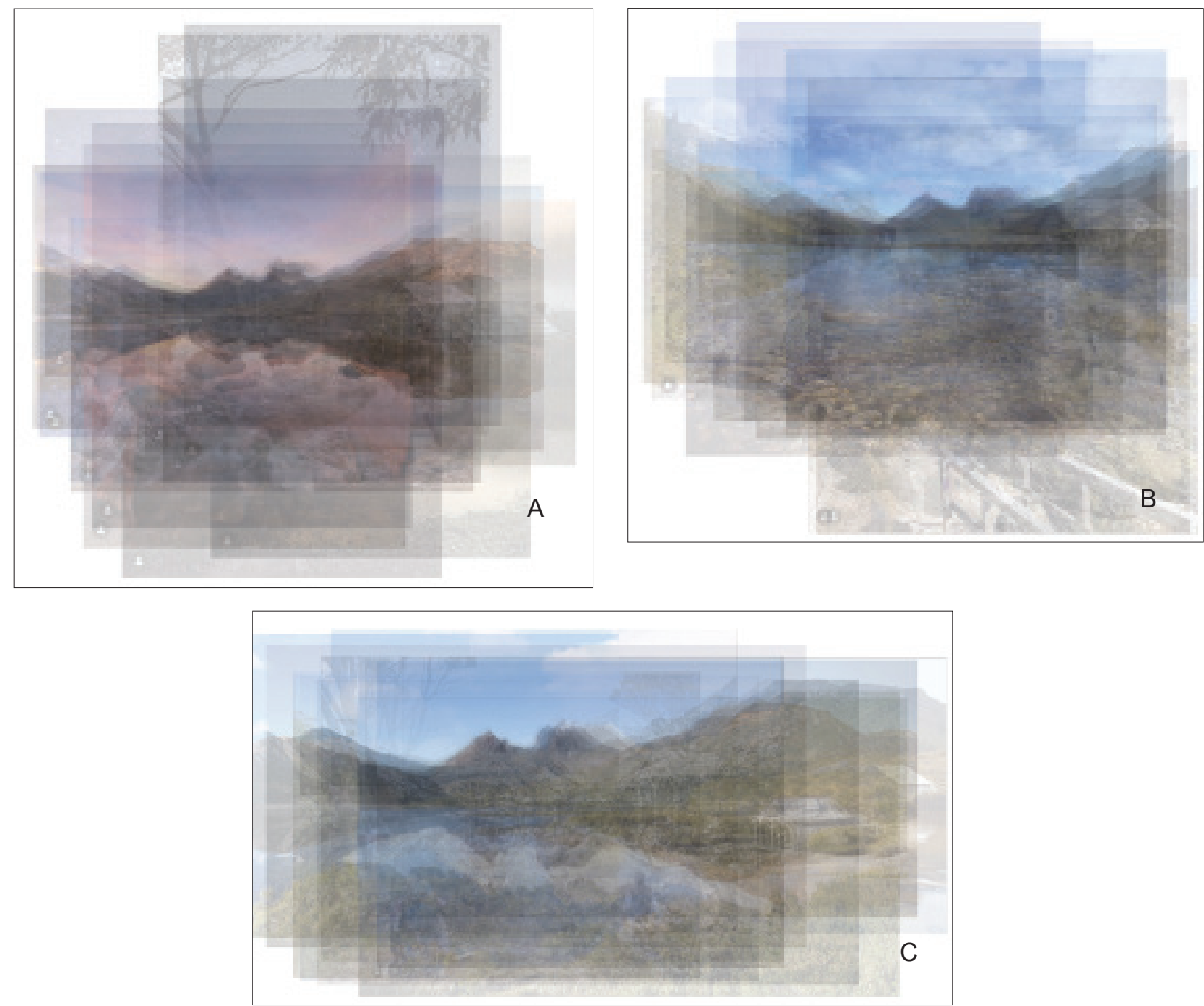

FIG. 3 - Photographic average composites (PAC) of Dove Lake, Cradle Mountain, Tasmania. PAC were created from the overlay of multiple images sourced from (A) Discover Tasmania; (B) Instagram; and (C) Google Images search.

The Discover Tasmania images had the highest percentages of geometric design (table 3). The Google Images shots had the highest percentages of extended long landscape shots and the greatest proportion of presence of water (table 3). The promotional images had the highest proportions of composition by thirds, terrestrial scenes, mountains, daytime shots and very wide shot figures (table 3).

Most of the differences between the images taken at Cradle Mountain and those at Freycinet reflected differences in their physical environment, some possible exceptions being more medium close-up figures and split images at Cradle Mountain and more aerial shots and use of geometric composition at Freycinet (table 4).

The PACs of Cradle Mountain differed in the contrast between dawn and dusk skies in the Discover Tasmania images (fig. 3A), compared to clear daytime skies in the Google (fig. 3C) and Instagram images (fig. 3B), and the wider frame and greater complexity of the Google PAC compared to the others. At Freycinet, the most popular Discover Tasmania image was from Mt Amos, with Wineglass Bay sitting like a lake below, framed by mountains (fig. 4A). The most popular Instagram image was from the Wineglass Bay lookout (fig. 4B). The most popular Google Image was of Wineglass Bay from the south (fig. 4C).

\section{DISCUSSION}

This study highlights the complex feedbacks between promotional/ professional images and tourist images. The current rise in user-generated content for advertising (or 'influencing' as it has been repackaged) through social media, has added complexity into image sources and their feedbacks beyond the simple influence model (Stephchenkova \& Zhan 2013).

It was expected that Google Image shots and promotional material would represent the professional aspect of the study, and Instagram and Discover Tasmania would represent the perceptions of the tourist. However, the images from Discover Tasmania were very similar to professional material and promotional images. Despite Discover Tasmania images being sourced from Instagram, the former had a closer relationship to the artistic Google Images than 

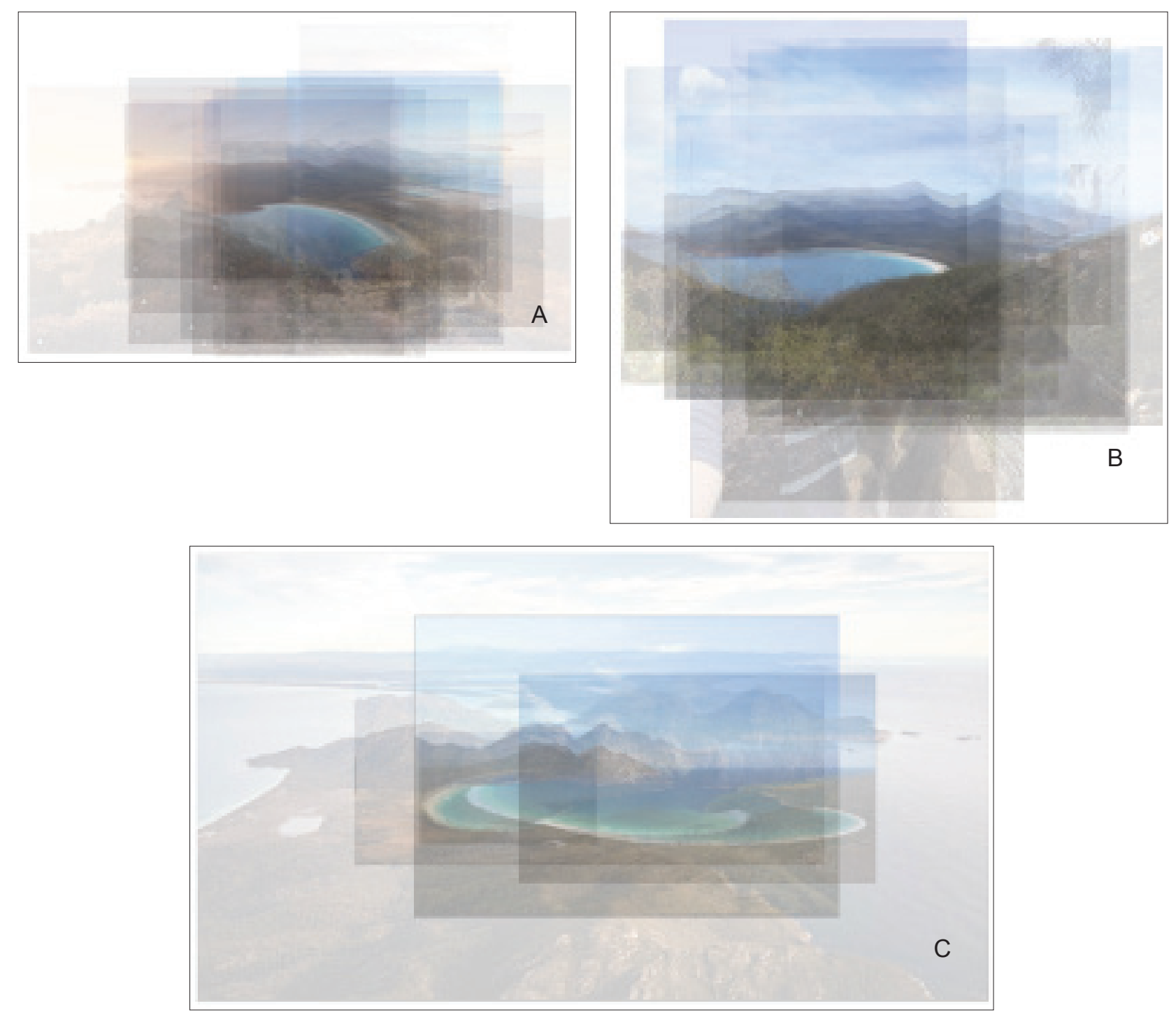

FIG. 4 - Photographic average composites (PAC) of (A) Mount Amos; (B) Wineglass Bay lookout; and (C) Freycinet Peninsula at Freycinet National Park, Tasmania. PAC were created from the overlay of multiple images sourced from (A) Discover Tasmania; (B) Instagram; and (C) Google Images searches.

to those in the Instagram pool. As Instagram were more related to Google Images and promotional material, it is likely that the images from the Instagram pool were those that conformed to mise en scène principles and a particular aesthetic related to time of day. Google Images and promotional material were related to Instagram and Discover Tasmania, emphasising that there is a complicated feedback process between image sources.

While tourists may be influenced to seek the reality of an image, they may not necessarily be able to seek the optimal photographic timing (Stylianou-Lambert 2012) because of a short visit or a lack of compositional skills. The Discover Tasmania PAC of Cradle Mountain is reminiscent of paintings from the Romantic period containing uncultivated and undeveloped landscape, mood lighting, warm hues and figures dwarfed by the landscape (fig. 3a). The romantic gaze symbolises solitude and undisturbed natural beauty (Urry 2005, Pan et al. 2014). Tourism images have been also been found to prefer warmer hues (Yu et al. 2020).
The high degree of similarity of promotional material to Instagram shots may indicate that the creators of the material have a strong understanding of tourist preferences or that images used in promotions were created by tourists. User-generated content is believed to have high authenticity, and therefore more likely to induce feelings and behaviours generated by emotions such as envy and desire than more professional work (Hajli et al. 2018). Tourists, therefore, may be both the consumer and the producer (StylianouLambert 2012).

Previous studies have highlighted that the perception of beauty is influenced by social and cultural climate (Urry \& Larsen 2011). Natural features, artefacts and photographic technique were largely constant between the two tourist icons, suggesting a constancy of society and culture. Natural features such as vegetation and mountains in this study were depicted using geometric shape and symmetry. Natural features such as the curvature of a beach and the mirrored reflection of a lake provided a strong base for composition. 
Tourists desire the unspoilt and remote (StylianouLambert 2012), preferably containing relative relief and water (Mendel \& Kirkpatrick 1999). Indicators of development are often omitted (Stylianou-Lambert 2012). However, I sampled images that were taken by tourists that featured artefacts. Artefacts, such as wooden boardwalks, when snaking off into the distance or between trees, can have aesthetic appeal. The information from tourist images can help architects design artefacts that are less obtrusive, or even attractive, in a landscape.

Discover Tasmania had a high incidence in traditional landscape techniques of advanced composition and conscious timing of day for optimal lighting. As they are mise en scène elements, it could be inferred that Discover Tasmania was biased towards 'mood' images, which is reinforced by the PAC. The aquamarine water and white sand beaches highlighted in the PAC reveal that colour, hue, brightness and saturation is a mise en scène element that is worth consideration in future studies (Yu et al. 2020).

Google Image's advanced landscape camera shots, perspective and inclusion of artefacts and landscape elements, reflects advanced photographic equipment and technique. The traditional photographic landscape technique is further reflected in the homogeneity of landscape orientation in the PAC. The mise en scène in the Google Images shots contrasts with Discover Tasmania in offering a new perspective and enhanced landscape detail. Although time of day did not differ between Freycinet and Cradle Mountain, visual analysis of the PAC reveals that the average time of day was early in the morning when light was still of photographic quality. Landscapes that contained mountains and water, were more desirable than the exclusive framing of a mountain or water (Smrekar $e t$ al. 2016), while beaches that are deserted and pristine are highly desirable (Stylianou-Lambert 2012). The rustic shed at Dove Lake adds further appeal, like water, by softening the sharpness of the mountain.

Promotional material was similar to Google Images shots in relation to perspective and landscape elements. Mountains were found to be of high incidence; however, the limitation of this finding is that, at Cradle Mountain, the mountain is of iconic landscape value, whereas the mountain range at Freycinet serves more as a backdrop to the iconic landscape value of Wineglass Bay.

Instagram contrasted with Google Images, promotional material and Discover Tasmania in that the content was centralised around a human figure in the landscape. A mid shot places emphasis on the figure while keeping the background visible. The tourist gaze produces images that allow one to be seen in the desirable location (Hajli et al. 2018). It is striking that the PAC are very similar in visual appearance between Freycinet and Cradle Mountain. The images are clustered together, suggesting that the majority are taken from a similar viewpoint; the overall colour of the images is similar as majority of images are taken during the day and adhere to the traditional landscape format. The PAC reaffirm the aforementioned notion that tourists travel to see the iconic landscape value irrespective of the time of day. Image conventions are passed on through advertising and promotional material, influencing the tourist gaze (Stylianou-Lambert 2012). As an example, the Instagram and Google PAC bear strong a similarity in framing, orientation and content. It could also be argued that these visual conventions were established in painting, decades before the invention of photography (Urry \& Larsen 2011).

An unexpected finding of this present study, revealed by the PAC, was the influence of photographic equipment on the tourist gaze. This effect is most clearly illustrated in the Cradle Mountain PACs which successively shorten in scene down the cascade of technical ability from Google Images, to Discover Tasmania to Instagram. When comparing the Cradle Mountain and Freycinet Instagram PACs, it is striking that they bear such a strong resemblance.

Visualisation of data through the PAC technique is a new method to validate content and mise en scène analysis. It is an exciting way to reveal patterns and relationships previously not considered and to visualise data sets for science communication.

\section{REFERENCES}

Australian Bureau of Statistics 2018: Australian Demographic Statistics. Canberra: Australian Bureau of Statistics. https://www.abs.gov.au/ausstats/abs@.nsf/lookup/ 3101.0Media\%20Release1Dec\%202018.

Bergh, R., Eyck, G., Eijck, G. \& Naafs, S. 2018: To Infinity and Beyond. Breda: The Eriskay Connection, Amsterdam: $232 \mathrm{pp}$.

Beza, B. 2010: The aesthetic value of a mountain landscape: a study of the Mt. Everest Trek. Landscape and Urban Planning 97: 306-317.

Choi, T. \& Sung, Y. 2018: Instagram versus Snapchat: Selfexpression and privacy concern on social media. Telematics and Informatics 35(8): 2289-2298.

Daniel, T. \& Meitner, M. 2001: Representational validity of landscape visualizations: The effects of graphical realism on perceived scenic beauty of forest vistas. Journal of Environmental Psychology 21: 61-72.

DPIPWE 2016: Tasmanian Wilderness World Heritage Area Management Plan 2016, Department of Primary Industries, Parks, Water and Environment, Hobart: 240 pp

Felton, N., Ehmann, S. \& Klanten, R. 2016: Photoviz. Gestalten, Berlin: 256 pp.

Geoscience Australia 2020: Area Of Australia - States And Territories, https:/www.ga.gov.au/scientific-topics/national-locationinformation/dimensions/area-of-australia-states-andterritories (accessed 20 September 2020).

Giannetti, L. 2014. Understanding Movies. 13th edn. Pearson Education Inc., London: 550 pp.

Hajli, N., Wang, Y. \& Tajvidi, M. 2018: Travel envy on social networking sites. Annals of Tourism Research 73: 184-189.

Kirillova, K., Fu, X., Lehto, X. \& Cai, L. 2014: What makes a destination beautiful? Dimensions of tourist aesthetic judgment. Tourism Management 42: 282-293.

Linton, D. 1968: The assessment of scenery as a natural resource. Scottish Geographical Magazine 84: 219-238.

Mendel, L. \& Kirkpatrick, J.B. 1999: Assessing temporal changes in the reservation of the natural aesthetic resource using pictorial content analysis and a grid-based scoring system - the example of Tasmania, Australia. Landscape and Urban Planning 43: 181-190. 
Pan, S., Lee, J. \& Tsai, H. 2014: Travel photos: Motivations, image dimensions, and affective qualities of places. Tourism Management 40: 59-69.

Patsfall, M., Feimer, N., Buhyoff, G. \& Wellman, J. 1984: The prediction of scenic beauty from landscape content and composition. Journal of Environmental Psychology 4: 7-26.

Paül i Agustí, D. 2018: Characterizing the location of touris images in cities. Differences in user-generated images (Instagram), official tourist brochures and travel guides. Annals of Tourism Research 73: 103-115.

Phelps, A. 1986: Holiday destination image - the problem of assessment. Tourism Management 8: 168-180.

Pickering, C., Chelsey, W.S., Barros, A. \& Rossic, S.D. 2020: Using social media images and text to examine how tourists view and value the highest mountain in Australia. Journal of Outdoor Recreation and Tourism 29: 1-12.

Schirpke, U., Tasser, E. \& Tappeiner, U. 2013: Predicting scenic beauty of mountain regions. Landscape and Urban Planning 111: 1-12.

Shafer, E. \& Brush, R. 1977: How to measure preferences for photographs of natural landscapes. Landscape Planning 4: $237-256$.

Smrekar, A., Polajnar Horvat, K. \& Erhartič, B. 2016: The beauty of landforms. Acta Geographica Slovenica 56: 321-335.

Stephchenkova, S. \& Zhan, F. 2013: Visual destination images of Peru: comparative content analysis of DMO and usergenerated photography. Tourism Management 36: 590-601.

Stylianou-Lambert, T. 2012: Tourists with cameras. Annals of Tourism Research 39: 1817-1838.

Tasmania Parks \& Wildlife Service 2019: Visitors To Selected Parks \& Reserves 2018-2019, https://parks.tas.gov.au/Documents/ Visitors $\% 20$ to $\% 20$ selected $\% 20$ parks $\% 20 \% 26 \% 20$ reserves\%202018-2019.pdf (accessed 20 September 2020).
Tasmania Parks \& Wildlife Service 2020: About the Tasmania Parks and Wildlife Service | Parks \& Wildlife Service Tasmania, https://parks.tas.gov.au/about-us (accessed 19 September 2020)

Tieskens, K., Van Zanten, B., Schulp, C. \& Verburg, P. 2018 Aesthetic appreciation of the cultural landscape through social media: an analysis of revealed preference in the Dutch river landscape. Landscape and Urban Planning 177: $128-137$.

Tourism Tasmania 2016: Asia Engagement Marketing Strategy. Tourism Tasmania, Hobart: $25 \mathrm{pp}$.

Tourism Tasmania 2019a: Tourism Fast Facts. Tourism Tasmania, Hobart: 1 pp.

Tourism Tasmania 2019b: Tourism Research. Tourism Tasmania, Hobart. https://www.tourismtasmania.com.au/_data/ assets/pdf_file/0008/84635/2019-Q2-Tasmanian-TourismSnapshot-June-2019-TVS-IVS-NVS.pdf

University of Tasmania 2019. Understanding Social Media Use in The Sensing Tourist Travel Study - Tourism Tracer, https:// tourismtracer.com/understanding-social-media-use-in-thesensing-tourist-travel-study/ (accessed 21 March 2019).

Urry, J. 1995: Consuming Places. Routledge, London: 264 pp.

Urry, J. \& Larsen, J. 2011: The Tourist Gaze 3.O. SAGE Publications Ltd., London: $282 \mathrm{pp}$.

Wang, R., Zhao, J. \& Liu, Z. 2016: Consensus in visual preferences: The effects of aesthetic quality and landscape types. Urban Forestry \& Urban Greening 20: 210-217.

Yu, C., Xie, S. \& Wen, J. 2020: Coloring the destination: The role of color psychology on Instagram. Tourism Management 80: $104-110$.

(accepted 30 September 2020) 
